\title{
Araştırma Makalesi \\ Master-eğriler kinetik yönteminin izotermal olmayan selüloz pirolizine uygulanması ve piroliz işleminin termodinamik analizi
}

\author{
*Gamzenur ÖZSIN
}

$\ddot{\mathbf{O Z Z}}$

Piroliz gibi termokimyasal dönüşüm yöntemlerinin kinetiğinin modellenmesi biyorafineriler için en zorlu konulardan biridir. Temelde biyokütle pirolizinin, selüloz ile birlikte lignin ve hemiselüloz piroliz özelliklerinden etkilendiği bilinmektedir. Bu nedenle, bu çalışmada selülozun piroliz kinetiği ve termodinamiği incelenmiştir. Pirolize ait kinetik parametreler master eğriler ve Friedman yönteminin birleştirilmesi ile hesaplanmıştır. Selülozun aktif pirolizinin 263 ile $455{ }^{\circ} \mathrm{C}$ arasında gerçekleştiği saptanmıştır. Uygulanan Friedman yöntemi deneysel veriler ile çok iyi uyum sağladığı, termokimyasal dönüşüm işleminin aktivasyon enerjilerinin 150.8 ile $190.2 \mathrm{~kJ} / \mathrm{mol}$ arasında değiştiği ve pirolizin ortalama aktivasyon enerjisinin $164.3 \mathrm{~kJ} / \mathrm{mol}$ olduğu bulunmuştur. Katı hal bozunma süreçlerinde kullanılan kinetik yöntemlerin karşılaştırılması ile selüloz piroliz mekanizmasının düşük dönüşümlerde $(0<\alpha<0.5)$ difüzyon kontrollü bir bozunma işlemi $\left(\mathrm{D}_{3}\right)$ ile sürdüğü ve daha yüksek dönüşümlerde ise tepkime derecesine bağlı olduğu saptanmıştır.

Anahtar Kelimeler-Selüloz, piroliz, kinetik, master-ĕgri, termodinamik

*Sorumlu yazar iletişim: gamzenur.ozsin@bilecik.edu.tr (https://orcid.org/0000-0001-5091-5485)

Kimya Mühendisliği Bölümü, Mühendislik Fakültesi, Bilecik Şeyh Edebali Üniversitesi, 11230, Bilecik, Türkiye 


\title{
Application of master-plots kinetic method to non-isothermal cellulose pyrolysis and thermodynamic analysis of the pyrolysis process
}

\begin{abstract}
Kinetic modeling of thermochemical conversion methods such as pyrolysis is one of the most challenging issues for bio-refineries. It is known that cellulose together with hemicellulose and lignin pyrolysis mainly affect the characteristics of biomass pyrolysis. Therefore, cellulose pyrolysis kinetics and thermodynamics were investigated in this study. Kinetic parameters of the pyrolysis process were calculated by a combined method of master-plots and Friedman method. Active pyrolysis of cellulose is found to occur between 263 and $455{ }^{\circ} \mathrm{C}$. Applied Friedman method was perfectly fitted with the experimental data and activation energy of the thermochemical conversion process was found between 150.8 and $190.2 \mathrm{~kJ} / \mathrm{mol}$ while the mean activation energy of pyrolysis was $164.3 \mathrm{~kJ} / \mathrm{mol}$. The comparison of kinetic models used of solid-state thermal decomposition processes indicated that the cellulose pyrolysis mechanism is a diffusion-controlled $\left(\mathrm{D}_{3}\right)$ degradation process at lower conversions $(0<\alpha<0.5)$ and the process can be explained by reaction-based mechanisms at higher conversion degrees.
\end{abstract}

\section{Keywords-Cellulose, pyrolysis, kinetic, master-plot, thermodynamics}




\section{INTRODUCTION}

Renewable biomass sources have become a major source of energy and chemicals for mankind for a long time. By the help of the thermochemical processes, value-added products may be obtained from unlimited biomass sources which may substitute fossil resources. Biomass offers several advantages since it has lower cost and high conversion efficiency, it contributes to the recovery of degraded land and increase biodiversity. Besides biomass derived fuels do not contribute to the accumulation of carbon dioxide in the atmosphere [1].

Pyrolysis as an effective thermochemical conversion process transforms biomass species into products which are in gaseous, liquid and solid state. The liquid product of the biomass pyrolysis (bio-oil) may be processed to produce alternative liquid fuels and numerous fine chemicals [2-5]. The gaseous product of the process can be used as fuel for industrial combustion purposes and used as a source of heat for the pyrolysis process itself $[1,6]$. On the other hand, the solid product, bio-char, can play an significant role in water remediation, soil amendment, and energy storage systems. The mentioned applications are highly related to its polyaromatic structure, intrinsic surface functional groups including heteroatoms and textural characteristics [7, 8].

During the biomass pyrolysis process, the main structures of the lignocellulosic matrix (as cellulose, hemicellulose, and lignin) are thermally cracked to smaller molecules under an inert atmosphere. Undoubtedly knowledge about biochemical composition of biomass as well as possible chemical conversions to tailor this composition has drawn particular interest in order to utilize bio-oil via pyrolysis process as a sustainable feedstock for the production of synthetic fuels and fine chemicals [9]. In order to achieve process design and optimization of the next generation feasible pyrolysis technologies detailed modeling studies are necessary [10]. By having a better understanding of the biomass pyrolysis led to a more accurate techno-economic assessment of potential biomass conversion processes [11]. At this point, understanding and predicting pyrolytic behavior of cellulose is of great importance for bio-refineries because typical dry biomass fuels consist of about $50 \%$ cellulose by weight [12] although variations in the biochemical composition of biomass depend on the type and part of the plant. Moreover, heterogeneous pyrolysis reactions along with heat and mass transfer occur during thermal degradation in the condensed phase [13].

To study the kinetics and to explicate thermal stabilities of materials thermogravimetric analysis (TGA) has been accepted to be an effective and reliable tool [14]. By the help of sensitive measurement of weight loss during both isothermal and non-isothermal modes, the kinetics of the thermally stimulated decomposition processes may be determined. In this study, a study on the kinetic analysis of cellulose pyrolysis based on nonisothermal thermogravimetry was performed and the empirical kinetic parameters together with the prevailing kinetic model were determined via master-plots.

\section{MATERIALS AND METHODS}

\section{A. Characterization of cellulose sample}

Microcrystalline cellulose was obtained from Sigma Aldrich (CAS Number: 9004-34-6) and used in the experiments without any treatment. It is known that cellulose is a linear polysaccharide which typically includes $\mathrm{d}$-glucose monomers [15]. Long-chain of glucose units of cellulose is known to be linked by $\beta$-(1-4) glycosidic bonding an all biomass types. But, end groups of the cellulose chain, degree of polymerization, and crystallinity depends on the structure of the biomass species [16]. The degree of polymerization of cellulose is highly depended on its source and cellulose is composed of crystalline and amorphous regions based on the degree of organization of its structure [17,18]. Prior to the thermogravimetric analysis experiments, elemental analysis together with SEM analysis was performed and the FT-IR spectrum was obtained to gain information about the chemical and the physical structure of the cellulose sample which is used in thermogravimetric analysis. Elemental analysis was carried out by LECO-CHN elemental analyzer, FT-IR spectrum was gained via Perkin Elmer Spectrum 100 spectrometer and SEM analysis was performed using Zeiss Supra VP40 microscope. The FT-IR spectra together with the building unit of cellulose is presented in Figure 1. The absorption band between 3500 and $3100 \mathrm{~cm}^{-1}$ in the spectrum is assigned to hydroxyl groups stretching. Bands at between 2840 and 3030 $\mathrm{cm}^{-1}$ assigned to stretching vibrations of C-H group in glucose unit. The relatively small peak around $1150 \mathrm{~cm}^{-1}$ is attributed to the $\mathrm{C}-\mathrm{O}$ antisymmetric bridge stretching. Moreover, the $\mathrm{HCH}$ and $\mathrm{OCH}$ in-plane bending 
vibrations approximately at $1430 \mathrm{~cm}^{-1}$ and the vibration near $1060 \mathrm{~cm}^{-1}$ is assigned to -C-O-group of secondary alcohols and ethers of cellulose backbone were observed in the FT-IR spectra of cellulose [19-21]. Figure 2 shows SEM micrographs of cellulose under various magnifications. The surface of the cellulose was heterogeneous and fragmented. Also, some undulating surfaces appeared in secondary electron images of the cellulose sample. According to the elemental analysis results, cellulose had carbon and hydrogen contents of 42.38 and $6.06 \mathrm{wt} \%$, respectively. Oxygen content was found from the difference as $51.56 \mathrm{wt}$. \% considering that nitrogen was below $0.1 \mathrm{wt}$. $\%$. By the help of elemental analysis $\mathrm{H} / \mathrm{C}$ and $\mathrm{O} / \mathrm{C}$ ratio of cellulose was calculated as 1.7 and 0.91 , respectively which are used for characterization of solid fuels.

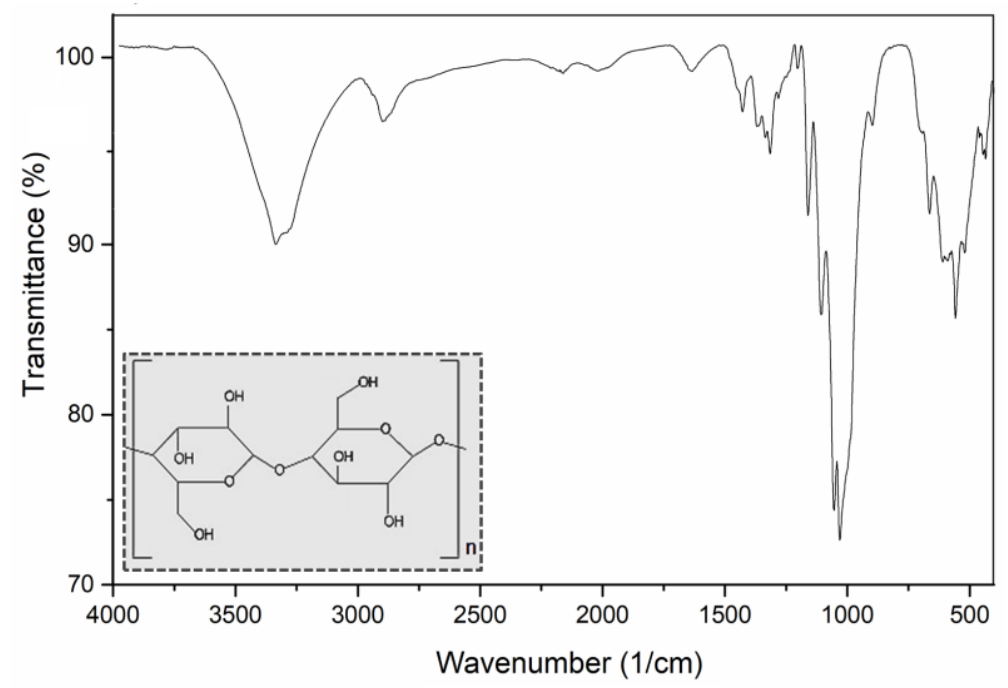

Figure 1. FT-IR spectrum of cellulose

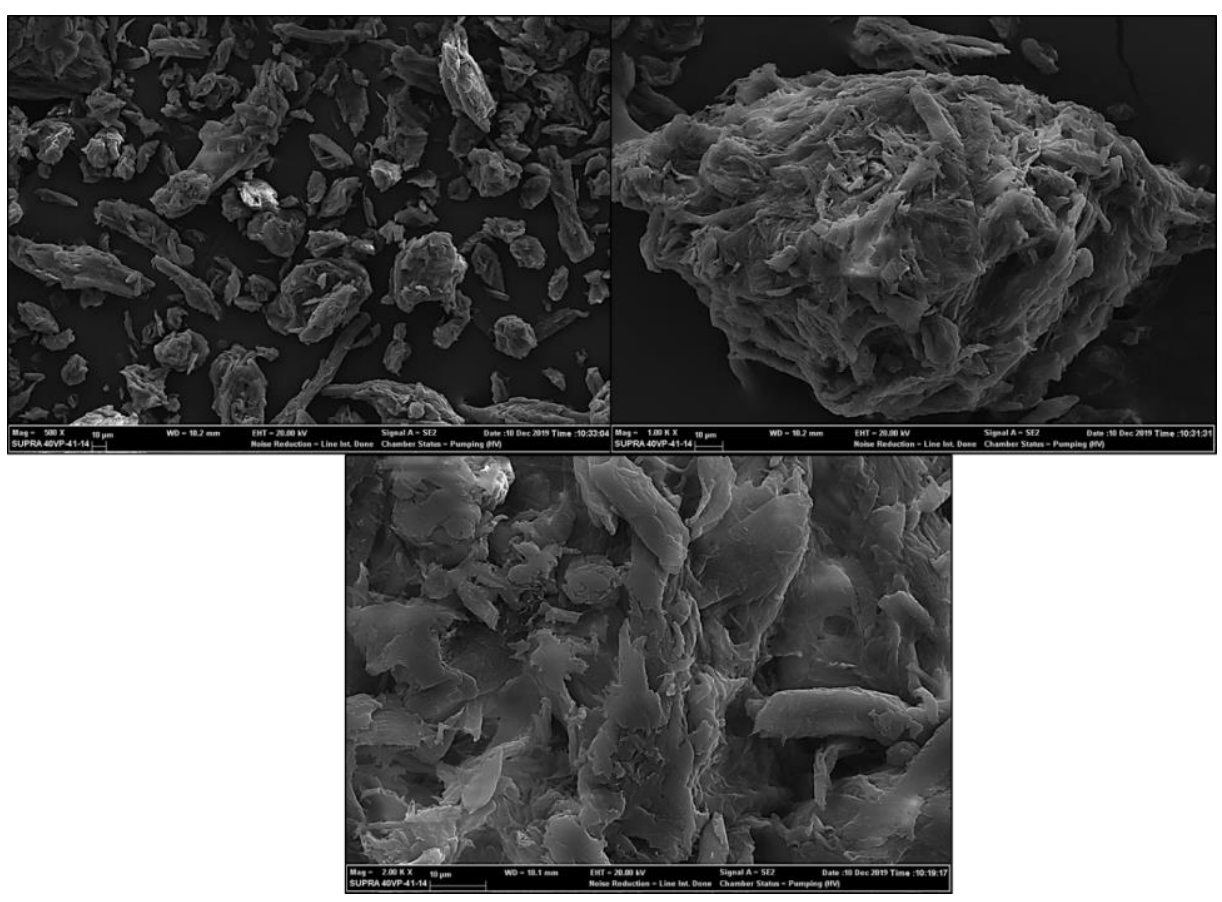

Figure 2. SEM micrographs of cellulose at different magnifications $(500,1000$ and 2000x) 


\section{B. Thermogravimetric analysis experiments}

TGA of cellulose was carried out using a Seteram Labsys-Evo thermogravimetric analyzer. Nonisothermal experiments were performed at heating rates of $5,10,20$ and $40^{\circ} \mathrm{C} / \mathrm{min}$ to scan the samples in the temperature range of $25^{\circ} \mathrm{C}$ to $1000{ }^{\circ} \mathrm{C}$. To mitigate the difference of heat and mass transfer, loaded sample amount to an alumina crucible was kept low (as $10 \mathrm{mg}$ approximately). The gas flow rate for all experiments was maintained at $20 \mathrm{ml} / \mathrm{min}$ and the mass vs time and temperature data were recorded by the help of the software of the TGA apparatus. TGA data was corrected using a preliminary blank experiment and three replications were carried out in order to maintain reproducibility.

\section{Theory of TGA-based kinetics and thermodynamics}

The fundamental TGA-based kinetic calculation method is based on the calculation of conversion degree $(\alpha)$ from the mass loss data as a function of temperature or time. The conversion degree is calculated by:

$$
\alpha=\frac{w_{o}-w_{t}}{w_{o}-w_{f}}
$$

where; $\mathrm{w}_{\mathrm{t}}$ is sample mass at time $\mathrm{t}$ or temperature $\mathrm{T}, \mathrm{w}_{\mathrm{o}}$ and $\mathrm{w}_{\mathrm{f}}$ are sample weights at the onset and at offset of the reaction, respectively. Pyrolysis reactivity index $\left(R_{p}\right)$, which may be beneficial to conclude reactivities of the system components, can be calculated according to the following formula:

$$
R_{p}=\frac{1}{w_{o}}\left(\frac{d w}{d t}\right)_{\max }
$$

where $(\mathrm{dw} / \mathrm{dt})_{\max }$ is the maximum pyrolysis rate and $\mathrm{w}_{\mathrm{o}}$ is the initial weight. A general expression for nonisothermal kinetic methods with a constant heating rate $(\beta=\mathrm{dT} / \mathrm{dt})$ kinetic of the process is characterized by two functions, as temperature function $(\mathrm{k}(\mathrm{T}))$ and fractional conversion function $(\mathrm{f}(\alpha))$, as given in Eq. 3:

$\frac{d \alpha}{d t}=\beta \frac{d \alpha}{d T}=k(\mathrm{~T}) \mathrm{f}(\alpha)$

Since Arrhenius equation explains temperature dependency of rate by expressing rate constant, $\mathrm{k},[\mathrm{k}=\mathrm{A} \exp (-$ $\left.E_{a} / R T\right)$ ] (where $E_{a}$ is the activation energy, $A$ is the pre-exponential factor and $R$ the gas constant), the rate equation can be modified as given in Eq. 4:

$\beta \frac{d \alpha}{d T}=A \exp \left(-\frac{E_{a}}{R T}\right) f(\alpha)$

Integration of both sides of Eq. (4) gives:

$\int_{0}^{\alpha} \frac{d \alpha}{f(\alpha)}=g(\alpha)=\frac{A}{\beta} \int_{T_{o}}^{T} \exp \left(-\frac{E_{a}}{R T}\right) d T$

where $g(\alpha)$ is the function of the integrated form of conversion degree. On the other hand, the kinetic model $f(\alpha)$ is related with a physical decomposition model. The $\mathrm{f}(\alpha)$ and $\mathrm{g}(\alpha)$ functions which are used in this study with abbreviations are listed in Table 1. In order to calculate activation energy with respect to conversion degree isoconversional methods such as Friedman method [22] may be applied to obtain kinetic parameters for complex reaction profiles. The linear form of the Friedman is given in Eq. 6 . 


$$
\ln \left(\beta \frac{d \alpha}{d T}\right)=\ln A+\ln f(\alpha)-\frac{E_{a}}{R T}
$$

However, iso-conversional methods cannot determine the exact kinetic mechanism of individual of the thermal processes. So, the model-based approaches show powerful cutting-edge mathematical predictions to determine the best kinetic model of complex reactions [23]. In order to estimate the kinetic mechanism of the pyrolysis master-plots method which is also known as Criado's method [24] was implemented together with Friedman method. By comparing experimental curves with theoretical curves which are characteristic for each reaction mechanism, models of pyrolysis and co-pyrolysis reactions are estimated in this technique. Eq. 7 shows the mathematical representation of the master plot method.

$$
\frac{z(\alpha)}{z(0.5)}=\frac{f(\alpha) g(\alpha)}{f(0.5) g(0.5)}=\left(T_{\alpha} / T_{0.5}\right) \frac{(d \alpha / d t)_{a}}{(d \alpha / d t)_{0.5}}
$$

The $[f(\alpha) g(\alpha) / f(0.5) g(0.5)]$ term of the equation is the reduced theoretical curve which indicates the characteristic of each reaction mechanism that was shown in Table 1. The right-hand side of the Eq. 7 is the reduced rate which was calculated according to the experimental data. The point where the conversion degree is equal to 0.5 is accepted as the reference point and comparing the theoretical master plots with the experimental plot gives the most appropriate reaction model [25] that will express the kinetics of the pyrolysis process. Statistical prediction of model fitting was also evaluated with respect to data fitting and estimation capabilities according to mean absolute deviation (MAD), mean square error (MSE), root mean square error (RMSE) and mean absolute percentage error (MAPE) calculations.

Thermodynamic parameters such as changes in enthalpy $(\Delta \mathrm{H})$, Gibbs free energy $(\Delta \mathrm{G})$ and entropy $(\Delta S)$ may be calculated after determination of the activation energy to a certain extent of the conversion degree. By the help of Eqs. 8-10, the thermodynamic parameters may be obtained.

$$
\begin{aligned}
& \Delta \mathrm{H}=\mathrm{E}_{a}-\mathrm{RT} \\
& \Delta G=E_{a}+R T_{m} \ln \left(\frac{K_{B} T_{m}}{h A}\right) \\
& \Delta S=\frac{\Delta H-\Delta G}{T_{m}}
\end{aligned}
$$

Here, $\mathrm{K}_{\mathrm{B}}$ expresses the Boltzmann constant $\left(1.381 \times 10^{-23} \mathrm{~J} / \mathrm{K}\right)$ and $\mathrm{h}$ shows the Plank constant $\left(6.626 \times 10^{-34} \mathrm{Js}\right)$. 


\begin{tabular}{|c|c|c|c|}
\hline Mechanisms & Symbol & $f(\alpha)$ & $\mathrm{g}(\alpha)$ \\
\hline \multicolumn{4}{|l|}{ Reaction order } \\
\hline First order & $\mathrm{R}_{1}$ & $(1-\alpha)$ & $-\ln (1-\alpha)$ \\
\hline Second order & $\mathrm{R}_{2}$ & $(1-\alpha)^{2}$ & {$\left[(1-\alpha)^{-1}-1\right]$} \\
\hline Third order & $\mathrm{R}_{3}$ & $(1-\alpha)^{3}$ & {$\left[(1-\alpha)^{-2}-1\right]$} \\
\hline One and half order & $\mathrm{R}_{1.5}$ & $(1-\alpha)^{3 / 2}$ & $\frac{2}{2\left[(1-\alpha)^{-1 / 2}-1\right]}$ \\
\hline \multicolumn{4}{|l|}{ Diffusion } \\
\hline One-dimensional diffusion & $\mathrm{D}_{1}$ & $\frac{\alpha}{\alpha}$ & $\alpha^{2}$ \\
\hline Two-dimentional diffusion (Valansi) & $\mathrm{D}_{2}$ & $\begin{array}{c}2 \\
{[-\ln (1-\alpha)]^{-1}}\end{array}$ & $\alpha+[(1-\alpha) \ln (1-\alpha)]$ \\
\hline Three-dimentional diffusion (Jander) & $\mathrm{D}_{3}$ & $\frac{3}{2}(1-\alpha)^{2 / 3}\left[1-(1-\alpha)^{1 / 3}\right]$ & {$\left[1-(1-\alpha)^{1 / 3}\right]^{2}$} \\
\hline $\begin{array}{l}\text { Three- dimentional diffusion } \\
\text { (Ginstling-Broushtein) }\end{array}$ & $\mathrm{D}_{4}$ & $\frac{3}{2}\left[(1-\alpha)^{1 / 3}-1\right]^{-1}$ & $\left(1-\frac{2 \alpha}{3}\right)-(1-\alpha)^{2 / 3}$ \\
\hline \multicolumn{4}{|l|}{ Nucleation or Growth } \\
\hline Power Law (n=1/2) & $\mathrm{P}_{1}$ & $2 \alpha^{1 / 2}$ & $\alpha^{1 / 2}$ \\
\hline Power Law (n=1/3) & $\mathrm{P}_{2}$ & $3 \alpha^{2 / 3}$ & $\alpha^{1 / 3}$ \\
\hline Power Law (n=1/4) & $\mathrm{P}_{3}$ & $4 \alpha^{3 / 4}$ & $\alpha^{1 / 4}$ \\
\hline Exponential Law & $\mathrm{P}_{4}$ & $\ln \alpha$ & $\alpha$ \\
\hline \multicolumn{4}{|l|}{ Sigmoidal Rate } \\
\hline Prout-Tomkins & $\mathrm{PT}_{1}$ & $\alpha(1-\alpha)$ & $-\ln (1-\alpha)$ \\
\hline
\end{tabular}




\section{RESULTS AND DISCUSSION}

\section{A. Thermogravimetric analysis}

The TGA and dTG thermograms obtained from the non-isothermal thermogravimetric experiments are given in Figure 4. According to the obtained thermograms, pyrolytic decomposition of cellulose initiated at $263{ }^{\circ} \mathrm{C}$ and ended at $455^{\circ} \mathrm{C}$ depending on the applied heating rate. A single dTG peak at every heating rate showed that pyrolytic degradation occurred at a single stage. The peak temperatures were between 329.9 and $363.7{ }^{\circ} \mathrm{C}$ for the heating rates between 5 and $40{ }^{\circ} \mathrm{C} / \mathrm{min}$. The carbonaceous solid char yields were about $21 \mathrm{wt} . \%$ of the initial weight of the sample for the active pyrolysis region. With the increase in temperature after this main decomposition zone, the mass-loss rate changed slowly and reached an asymptotic value near 15 wt. \% of the initial value. A literature survey on cellulose pyrolysis concluded that the passive pyrolysis region of cellulose after active pyrolysis zone involves rearrangement in a polycyclic structure and conversion of short substituent groups of the aromatic rings [27]. When the applied heating rate was changed from 5 to $40{ }^{\circ} \mathrm{C} / \mathrm{min}$ during nonisothermal runs, the reactivity values were progressively increased from 1.30 to $7.31 \% / \mathrm{min} . \mathrm{mg}$. The effect of the heating rate found similar to the typical fuel samples that may be used in the pyrolysis process. The profiles converge at the similar mass value of residual solid at the end of the hating process although the thermograms altered to higher temperature points with the heating rate. This observation related to the heating rate is attributed to the increase in the temperatures associated with the maximum devolatilization rate, as the heating rate increases [28]. It is known that higher residence times permit to existence of thermal gradients which may penetrate into the inner core of particles in the case of lower heating rates. Conversely, when the applied residence time was low, it could not allow thermal gradients to distribute evenly into the particle. This phenomenon resulted in high peak temperatures and intense dTG peaks at higher heating rates [29-31]. The mass-loss was during the degradation of the cellulose is associated with the formation of smaller volatiles such as carbon monoxide, carbon dioxide, methane, acetaldehyde, hydroxyacetone, hydroxyacetaldehyde, furfural, levoglucosan.

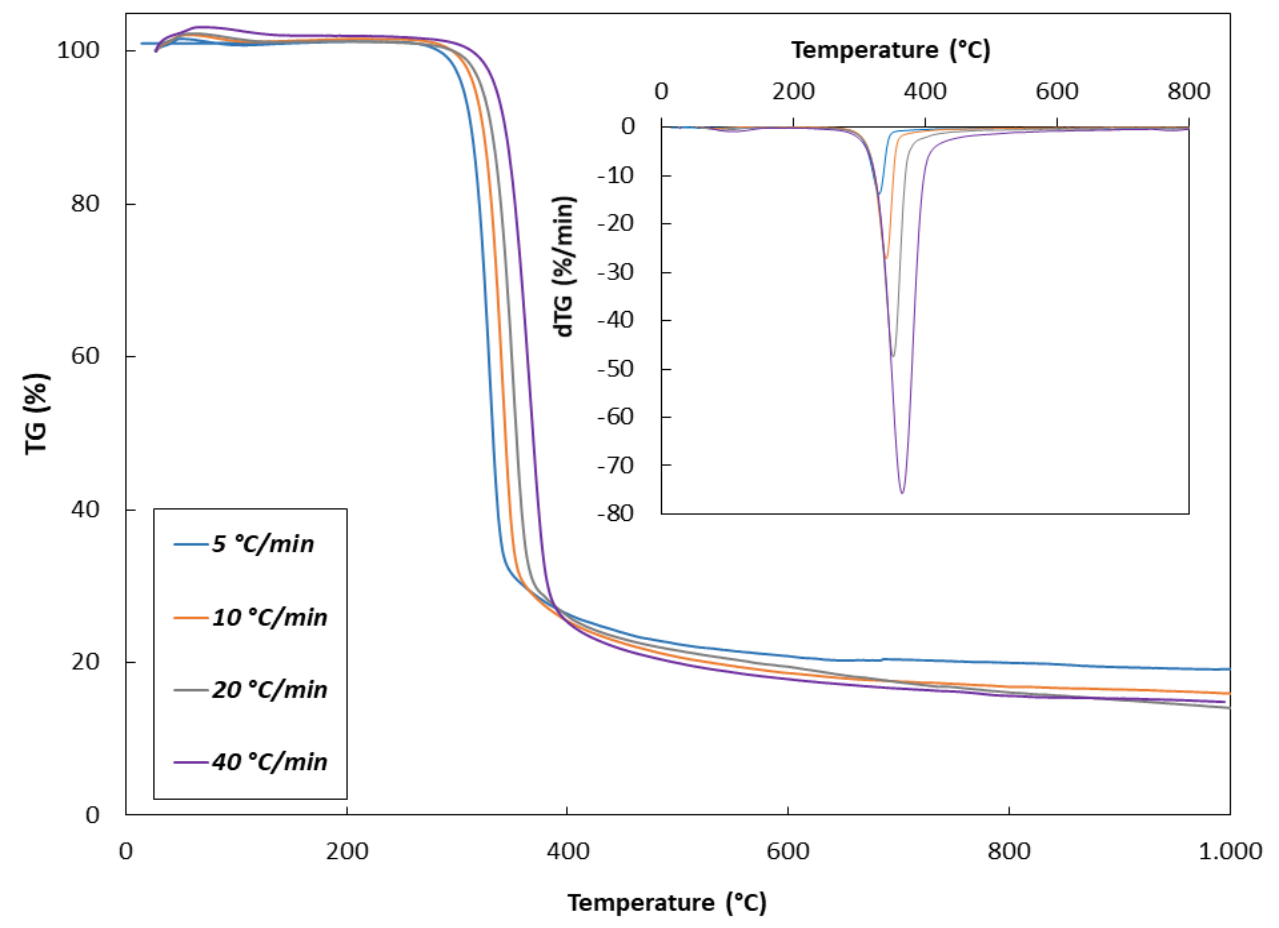

Figure 3. TG and dTG curves for cellulose pyrolysis at different heating rates 


\section{B. Determination of activation energy via iso-conversional Friedman method}

The establishment of the kinetic parameter of cellulose pyrolysis is vital for the implementation of thermochemical conversion processes like pyrolysis, gasification, and combustion. Therefore, kinetic studies of pyrolysis receive a great deal of attention in recent years since it is the basis of the thermochemical processes. Figure 5 depicts activation energy at various conversion degree based on Friedman method. The iso-conversional approach of the Friedman method does not require previous knowledge of the mechanism to predict the pyrolytic activation energy. The activation energy is defined as the minimum amount of energy required to initiate a reaction. Hence, higher activation energy shows lower reactivity and higher stability of the precursor during pyrolytic degradation. Besides, the numerical value of activation energy indicates the sensitivity of reaction rate to the possible temperature changes, thus larger rate increases are hypothesized for the reactions with higher activation energies [32]. The activation energy values predicted by Friedman calculation method were in the range of $150.79-190.23 \mathrm{~kJ} / \mathrm{mol}$ with an average value of 164.33 . The highest activation energy calculated at the initiation point of the pyrolysis at a conversion degree value of 0.1 , and then gradually decreased up to a conversion degree of 0.7 . This value at a conversion degree of 0.7 indicated that higher reactivity and lower stability at that point. Further increasing temperature after a conversion degree of 0.7 resulted in a slight increase till the end of the pyrolysis process. The changes in the value of activation energy with increasing conversion degree may indicate the occurrence of different decomposition mechanisms or of the dominant mechanism and reflect the kinetic complexity of cellulose pyrolysis. The pre-exponential factors were calculated and tabulated in Table 2. According to the results, they were found in the range of $2.89 \times 10^{9}-1.03 \times 10^{13} \mathrm{~s}^{-1}$ between conversions of 0.1 to 0.9 at different heating rates between 5 and $40{ }^{\circ} \mathrm{C} / \mathrm{min}$.

In a previous model-based study of Varhegyi et al. it is reported that the cellulose pyrolysis can be described by a single first-order model with approximate activation energy as $238 \mathrm{~kJ} / \mathrm{mol}$ at heating rates of 2 ${ }^{\circ} \mathrm{C} / \mathrm{min}$ or more [33]. According to the study of Gronli et al. activation energy values were between 234 and 264 $\mathrm{kJ} / \mathrm{mol}$ at $5{ }^{\circ} \mathrm{C} / \mathrm{min}$ while they were changed from 211 to 232 at $40{ }^{\circ} \mathrm{C} / \mathrm{min}$ [34]. When Antal et a. compared kinetic behaviours of different kinds of cellulose samples during pyrolysis at 1,10 and $65{ }^{\circ} \mathrm{C} / \mathrm{min}$ heating rate, they concluded that strongly depends on the type of cellulose. The activation energy values varied between 174 and $250 \mathrm{~kJ} / \mathrm{mol}$ depending on the characteristics of the sample and experimental conditions such as heating rate [35]. When Cornesa et al. applied different solid-state decomposition models to cellulose pyrolysis data which were calculated at heating rates 5 and $50{ }^{\circ} \mathrm{C} / \mathrm{min}$, activation energy changed between 193 and $294 \mathrm{~kJ} / \mathrm{mol}$. Moreover, they implied that cellulose pyrolysis in dynamic conditions can be described with acceptable accuracy by a first-order kinetic model and the probable deviations from this model may result from the fact that cellulose does not decompose by a single reaction step [36]. In another study which is carried out by Lin et al., the pyrolytic conversion of cellulose was fitted to two different first-order reaction models that assume the temperature difference between the thermocouple and specimen in TGA to be directly proportional to the heating rate and heat transfer at the sample boundary including the heat flow by endothermic pyrolysis reaction. As a consequence, they predicted activation energy of cellulose pyrolysis as $198 \mathrm{~kJ} / \mathrm{mol}$ [37]. Capart et el. investigated pyrolysis of micro granular cellulose in both a dynamic mode at constant heating rates between 1 and $11^{\circ} \mathrm{C} / \mathrm{min}$ and an isothermal mode at various temperatures, kept constant between 280 and $320^{\circ} \mathrm{C}$. The obtained data were found to be fitted with a reaction scheme consisting of two parallel reactions whose activation energies were in order of 202 and $255 \mathrm{~kJ} / \mathrm{mol}$ [38]. A recent study of Zhou et al. investigated cellulose pyrolysis using both a TGA and macro-TGA. A novel peak analysis-least square method was developed to analyse the experimental data and results showed that activation energy of cellulose pyrolysis was $279 \mathrm{~kJ} / \mathrm{mol} \mathrm{in}$ TGA while it was $291 \mathrm{~kJ} / \mathrm{mol}$ in macro-TGA [39]. Based on these previous kinetic studies, it is convenient to say that activation energy of the process is highly susceptible to the characteristics of the cellulose sample together with experimental and computational methods that were used. 

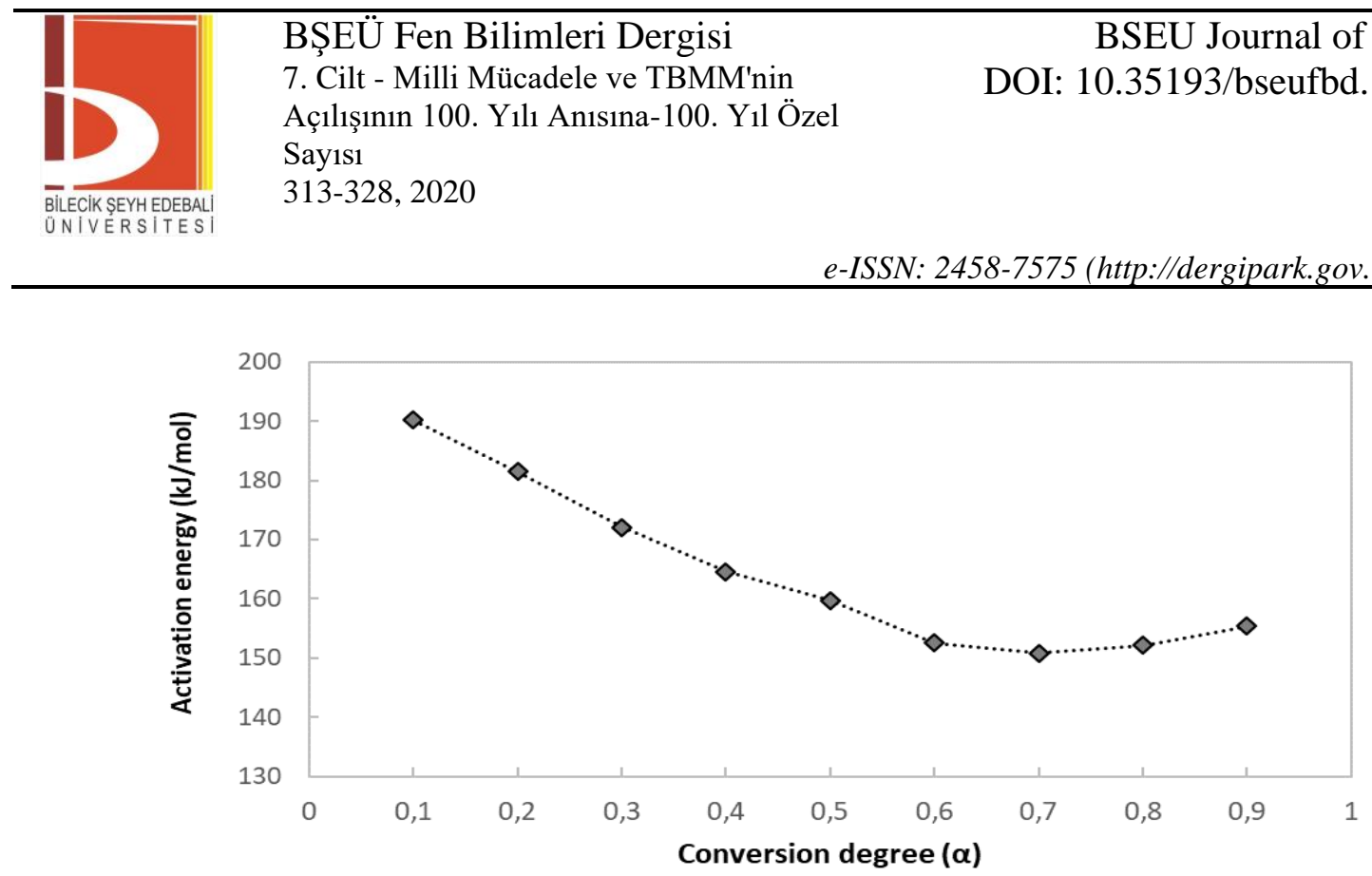

Figure 4. Variation of activation energy with conversion degree based on Friedman method

Table 2. Variations in the values of pre-exponential factor $\left(\mathrm{s}^{-1}\right)$ with conversion degree and heating rate

\begin{tabular}{|c|c|c|c|c|}
\hline \multirow[b]{2}{*}{$\alpha$} & \multicolumn{4}{|c|}{$\beta\left({ }^{\circ} \mathrm{C} / \mathrm{min}\right)$} \\
\hline & 5 & 10 & 20 & 40 \\
\hline 0.1 & $9.41 \times 10^{12}$ & $9.07 \times 10^{12}$ & $1.03 \times 10^{13}$ & $9.06 \times 10^{12}$ \\
\hline 0.2 & $1.58 \times 10^{12}$ & $1.58 \times 10^{12}$ & $1.83 \times 10^{12}$ & $1.67 \times 10^{12}$ \\
\hline 0.3 & $2.28 \times 10^{11}$ & $2.35 \times 10^{11}$ & $2.80 \times 10^{12}$ & $2.65 \times 10^{11}$ \\
\hline 0.4 & $4.91 \times 10^{10}$ & $5.19 \times 10^{10}$ & $6.32 \times 10^{10}$ & $6.19 \times 10^{10}$ \\
\hline 0.5 & $1.82 \times 10^{10}$ & $1.96 \times 10^{10}$ & $2.42 \times 10^{10}$ & $2.42 \times 10^{10}$ \\
\hline 0.6 & $4.07 \times 10^{9}$ & $4.51 \times 10^{9}$ & $5.68 \times 10^{9}$ & $5.84 \times 10^{9}$ \\
\hline 0.7 & $2.87 \times 10^{9}$ & $3.19 \times 10^{9}$ & $4.04 \times 10^{9}$ & $4.18 \times 10^{9}$ \\
\hline 0.8 & $3.76 \times 10^{9}$ & $4.17 \times 10^{9}$ & $5.26 \times 10^{9}$ & $5.42 \times 10^{9}$ \\
\hline 0.9 & $7.34 \times 10^{9}$ & $8.04 \times 10^{9}$ & $1.00 \times 10^{10}$ & $1.02 \times 10^{10}$ \\
\hline Average & $1.26 \times 10^{12}$ & $1.22 \times 10^{12}$ & $1.39 \times 10^{12}$ & $1.23 \times 10^{12}$ \\
\hline
\end{tabular}

\section{Determination of kinetic model}

As explained in Section II. (C), the reaction model of pyrolytic decomposition reactions could be obtained using the master-plots method. This method provides a mathematical approach to determine the most probable pyrolysis mechanism during the cellulose pyrolysis. By the help of comparing theoretical and experimental master plots $f(\alpha)$ and $g(\alpha)$ functions of the thermal degradation of the process can be estimated. Figure 6 shows the dependence of experimental master plots on the heating rate. When the applied heating rate was changed from 5 to $40{ }^{\circ} \mathrm{C} / \mathrm{min}$ gradually, the trend remained the same with increasing conversion degree. Although the shape of the experimental curves for all of the applied heating rates were similar, slight changes was observed due to the heat and mass transfer. It has been also reported that $\mathrm{z}(\alpha)$ is practically independent of the heating rate [40]. Therefore, master plots were evaluated for the determination of the kinetic mechanism over normalized conversion values for a heating rate of $10^{\circ} \mathrm{C} / \mathrm{min}$. The statistical parameters such as MAD, MSE, RMSE and MAPE were displayed in Table 3 in order to compare theoretical and experimental results during the active pyrolysis stage. These parameters express the forecasting errors on actual experimental observations quantitatively. Analysing Table 3, it was possible to verify that the cellulose pyrolysis cannot be satisfactorily described by a single type of mechanism over the whole conversion degree range between 0.1 and 0.9 . 


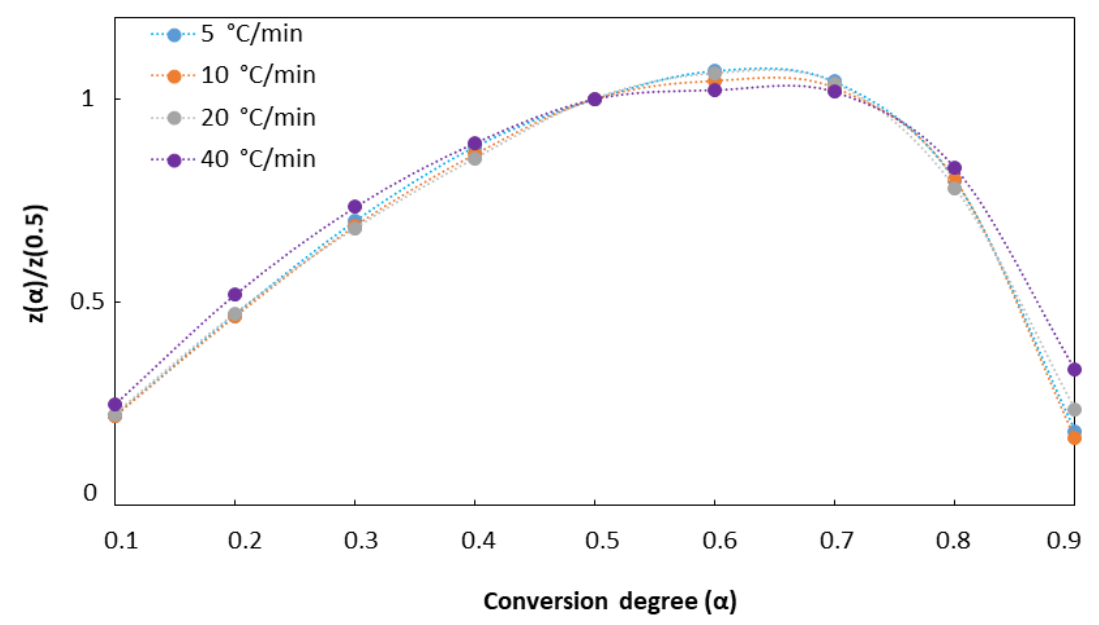

Figure 5. Experimental master plots at different heating rates for cellulose pyrolysis

Table 3. Statistical evaluation of the kinetic models for the cellulose pyrolysis $(\alpha=0.1-0.9)$

\begin{tabular}{ccccc}
\hline Mechanism & MAD & MSE & RMSE & MAPE (\%) \\
\hline $\mathrm{R}_{1}$ & 0.090 & 0.030 & 0.174 & 39.89 \\
$\mathrm{R}_{2}$ & 0.246 & 0.081 & 0.285 & 44.60 \\
$\mathrm{R}_{3}$ & 0.200 & 0.050 & 0.223 & 40.69 \\
$\mathrm{R}_{1.5}$ & 0.094 & 0.015 & 0.124 & 31.86 \\
$\mathrm{D}_{1}$ & 1.422 & 5.213 & 2.283 & 481.83 \\
$\mathrm{D}_{2}$ & 0.240 & 0.187 & 0.433 & 89.87 \\
$\mathrm{D}_{3}$ & 0.137 & 0.069 & 0.263 & 55.77 \\
$\mathrm{D}_{4}$ & 0.394 & 0.461 & 0.679 & 142.92 \\
$\mathrm{P}_{1}$ & 0.717 & 1.046 & 1.023 & 212.32 \\
$\mathrm{P}_{2}$ & 0.355 & 0.387 & 0.622 & 130.56 \\
$\mathrm{P}_{3}$ & 0.355 & 0.387 & 0.622 & 130.56 \\
$\mathrm{P}_{4}$ & 0.257 & 0.087 & 0.296 & 57.69 \\
$\mathrm{PT}_{1}$ & 0.356 & 0.217 & 0.465 & 105.90 \\
\hline
\end{tabular}

When the algebraic expressions of degradation mechanism as order-based reaction mechanisms, nucleation, and growth-based mechanisms and diffusion phenomena for the thermal decomposition process were evaluated, the theoretical and experimental master plots are obtained as shown in Figure 7. The theoretical curve which converges to experimental curve was specified as the dominant mechanism. The plots indicated that the pyrolysis process of cellulose cannot be fully described by a single reaction model throughout the whole active pyrolysis zone as it is concluded according to the previous statistical evaluation. The main mechanism changed as the conversion increased. It is observed from master plots that overlapping of best fitting of experimental data was achieved by $\mathrm{D}_{3}$ type mechanism at lower conversions $(0<\alpha<0.5)$. The experimental curve presented a change of shape when the conversion degree was 0.5 . It is convenient to say that diffusion takes an important role in the pyrolytic decomposition of cellulose at the initial stages.

Diffusion based models assume that the reaction rate is higher than reaction front propagation throughout the pyrolysis medium. Accordingly, the pyrolytic degradation reaction occurs at the boundary of the two phases like solid and gas. Therefore, the gas must diffuse into the solid to a reaction to progress. Theoretically, the pyrolysis begins in the outer layer of the precursor, and proceeds into the solid, by formation a layer of products. As the conversion increases by increasing the pyrolysis temperature, the thickness of the product layer around the sample. The formed product layer around the sample can obstruct the heat by adding additional diffusion resistance. Thus, diffusion becomes the rate-determining step, especially at lower conversion 
degrees or the degradation process $[41,42]$. Table 4 shows the percent error between the theoretical $\mathrm{D}_{3}$ curve and the experimental curve depending on the applied heating rate between conversion values of 0 and 0.5 . When the decomposition was proceeding further the mechanism shifted to $\mathrm{R}_{1}$ type of decomposition until a conversion degree of 0.7. On conversion degree of 0.8 , the mechanism followed the $\mathrm{R}_{1.5}$ type of reaction mechanism. During the latest stage of thermal decomposition at conversion degrees between 0.8 and 0.9 , the mechanism cannot be adequately predicted. To put it other words, the experimental results at a conversion degree of 0.9 cannot provide a suitable indication of the mechanism but it converges to the $\mathrm{R}_{2}$ type of mechanism. All in all, no precise solid-state decomposition model could express an exact description of the experimental master curves for the whole process including conversion degrees between 0.1 and 0.9 satisfactorily. According to the above discussed, the thermal decomposition of the cellulose can be described by complex pyrolysis reactions which include conversion of radicals to condensable and non-condensable volatiles together with char and can be related with the multiple phenomena occurring simultaneously.
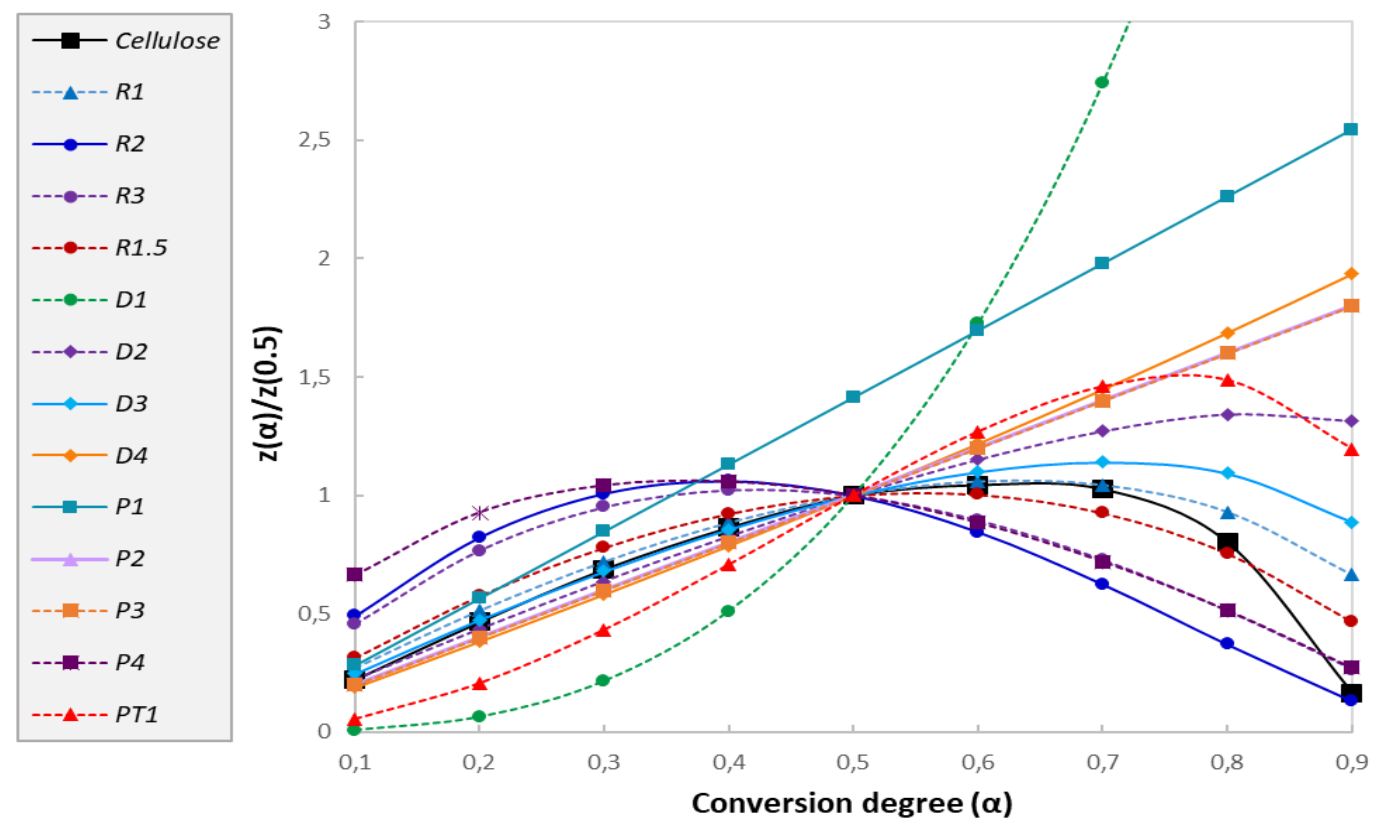

Figure 6. Theoretical and experimental master plots for cellulose pyrolysis $\left(\beta=10^{\circ} \mathrm{C} / \mathrm{min}\right)$

Table 4. Percent error between experimental and theoretical $\left(D_{3}\right)$ curves depending on the applied heating rate $(\alpha=0-0.5)$

\begin{tabular}{ccccc}
\hline \multicolumn{3}{c}{$\boldsymbol{\beta}\left({ }^{\circ} \mathbf{C} / \mathbf{m i n}\right)$} \\
\hline $\boldsymbol{\alpha}$ & $\mathbf{5}$ & $\mathbf{1 0}$ & $\mathbf{2 0}$ & $\mathbf{4 0}$ \\
\hline $\mathbf{0 . 2}$ & 11.48 & 10.70 & 9.41 & 0.07 \\
$\mathbf{0 . 3}$ & 1.41 & 2.14 & 0.06 & 7.90 \\
$\mathbf{0 . 4}$ & 2.83 & 1.19 & 0.55 & 4.04 \\
$\mathbf{0 . 5}$ & 2.96 & 0.82 & 0.00 & 0.00 \\
\hline Average & 0.00 & 0.00 & 2.18 & 4.18 \\
\hline
\end{tabular}




\section{E. Thermodynamics of cellulose pyrolysis}

In order to calculate the thermodynamic parameters for pyrolysis processes, active pyrolysis zone was chosen for analysis at a heating rate of $10{ }^{\circ} \mathrm{C} / \mathrm{min}$, because a relatively lower heating rate is known to provide more accurate results [43]. The results of the thermodynamic parameters were given in Table 5 to determine the favorability of the process and conclude pyrolytic potential of cellulose with the and status of the products. For the cellulose pyrolysis processes, the enthalpy changes were positive demonstrating the endothermic nature of the reaction. This was because enthalpy change during thermal decomposition demonstrates the variance in the level of energy between the reagents and stimulated intricate substance [44]. The value of mean enthalpy change through the whole conversion degree for cellulose was $159.25 \mathrm{~kJ} / \mathrm{mol}$. On the other hand, the degree of stability of a system may be estimated by the value of Gibbs free energy change. As the results indicated, the Gibbs free energy change varied with the conversion degree for both the pyrolysis processes. In the case of lower Gibbs free energy change, a higher favourability of the reaction is in question. The Gibbs free energy change for the pyrolysis of cellulose ranged between 169.20 and $191.00 \mathrm{~kJ} / \mathrm{mol}$ for the corresponding conversion degrees between 0.1 and 0.9. Entropy change indicates how close the system is to its thermodynamic equilibrium. A lower entropy change indicates a system that is near to its thermodynamic equilibrium and less reactive. Otherwise, a larger entropy change shows that the system is not close to its thermodynamic equilibrium and is more reactive. The minimum negative value of entropy change was $-38.32 \mathrm{~J} / \mathrm{mol}$ at a conversion degree of 0.7 .

Table 5. Thermodynamic parameters for cellulose pyrolysis

\begin{tabular}{cccc}
\hline $\boldsymbol{\alpha}$ & $\begin{array}{c}\Delta \mathbf{H} \\
(\mathbf{k j} / \mathbf{m o l})\end{array}$ & $\begin{array}{c}\Delta \mathbf{G} \\
(\mathbf{k j} / \mathbf{m o l})\end{array}$ & $\begin{array}{c}\Delta \mathbf{S} \\
(\mathbf{j} / \mathbf{m o l . K})\end{array}$ \\
\hline $\mathbf{0 . 1}$ & 185.31 & 191.00 & -9.25 \\
$\mathbf{0 . 2}$ & 176.54 & 186.18 & -15.69 \\
$\mathbf{0 . 3}$ & 167.04 & 180.95 & -22.63 \\
$\mathbf{0 . 4}$ & 159.54 & 176.82 & -28.12 \\
$\mathbf{0 . 5}$ & 154.69 & 174.16 & -31.68 \\
$\mathbf{0 . 6}$ & 147.39 & 170.14 & -37.03 \\
$\mathbf{0 . 7}$ & 145.66 & 169.20 & -38.32 \\
$\mathbf{0 . 8}$ & 146.96 & 169.93 & -37.40 \\
$\mathbf{0 . 9}$ & 150.13 & 171.72 & -35.14 \\
Average & 159.25 & 176.68 & -28.36 \\
\hline
\end{tabular}

\section{CONCLUSIONS}

In this study, cellulose pyrolysis was investigated and activation energy values calculated in active pyrolysis zone have shown different values depending on the conversion degree. The activation energy values obtained by Friedman iso-conversional method were in the range of $150.79-190.23 \mathrm{~kJ} / \mathrm{mol}$ with an average value of $164.33 \mathrm{kj} / \mathrm{mol}$. The master-plots revealed that the controlling mechanism of cellulose pyrolysis mechanism was diffusion and reaction order-based decomposition process. Also, thermodynamic parameters such as enthalpy change, Gibbs free energy change, and entropy change were reported at different conversion degrees. The value of mean enthalpy change through the whole conversion degree for cellulose was $159.25 \mathrm{~kJ} / \mathrm{mol}$. On the other hand, the values of mean Gibbs free energy change and mean entropy change were $176.68 \mathrm{kj} / \mathrm{mol}$ and - 
$28.36 \mathrm{j} / \mathrm{mol} . \mathrm{K}$, respectively. The data of the current study could provide insights into the future pyrolysis applications of cellulosic materials which have important bioenergy potentials.

\section{ACKNOWLEDGEMENTS}

The author acknowledges gratefully to the Carbon Materials Processing Group, Eskişehir Technical University for facilitating TGA experiments.

\section{REFERENCES}

[1] Guedes, R. E., A. S. Luna and A. R. Torres (2018). Operating parameters for bio-oil production in biomass pyrolysis: a review. Journal of analytical and applied pyrolysis, 129, 134-149.

[2] Fu, X., Q. Li and C. Hu (2019). Identification and structural characterization of oligomers formed from the pyrolysis of biomass. Journal of Analytical and Applied Pyrolysis, 144, 104696.

[3] Rony, A. H., D. Mosiman, Z. Sun, D. Qin, Y. Zheng, J. H. Boman IV and M. Fan (2018). A novel solar powered biomass pyrolysis reactor for producing fuels and chemicals. Journal of Analytical and Applied Pyrolysis, 132, 19-32.

[4] Pütün, A. E., B. B. Uzun, E. Apaydin and E. Pütün (2005). Bio-oil from olive oil industry wastes: Pyrolysis of olive residue under different conditions. Fuel Processing Technology, 87(1), 25-32.

[5] Kılıç, M., E. Pütün and A. E. Pütün (2014). Optimization of Euphorbia rigida fast pyrolysis conditions by using response surface methodology. Journal of analytical and applied pyrolysis, 110, 163-171.

[6] Goyal, H., D. Seal and R. Saxena (2008). Bio-fuels from thermochemical conversion of renewable resources: a review. Renewable and sustainable energy reviews, 12(2), 504-517.

[7] Correa, C. R., T. Hehr, A. Voglhuber-Slavinsky, Y. Rauscher and A. Kruse (2019). Pyrolysis vs. hydrothermal carbonization: Understanding the effect of biomass structural components and inorganic compounds on the char properties. Journal of Analytical and Applied Pyrolysis, 140, 137-147.

[8] Apaydın-Varol, E. and A. E. Pütün (2012). Preparation and characterization of pyrolytic chars from different biomass samples. Journal of Analytical and Applied Pyrolysis, 98, 29-36.

[9] Patwardhan, P. R., J. A. Satrio, R. C. Brown and B. H. Shanks (2010). Influence of inorganic salts on the primary pyrolysis products of cellulose. Bioresource technology, 101(12), 4646-4655

[10] Maduskar, S., V. Maliekkal, M. Neurock and P. J. Dauenhauer (2018). On the yield of levoglucosan from cellulose pyrolysis. ACS Sustainable Chemistry \& Engineering, 6(5), 7017-7025.

[11] Trendewicz, A., R. Evans, A. Dutta, R. Sykes, D. Carpenter and R. Braun (2015). Evaluating the effect of potassium on cellulose pyrolysis reaction kinetics. Biomass and bioenergy, 74, 15-25.

[12] Antal, M. J. J. and G. Varhegyi (1995). Cellulose pyrolysis kinetics: the current state of knowledge. Industrial \& Engineering Chemistry Research 34(3), 703-717.

[13] Zheng, M., Z. Wang, X. Li, X. Qiao, W. Song and L. Guo (2016). Initial reaction mechanisms of cellulose pyrolysis revealed by ReaxFF molecular dynamics. Fuel, 177: 130-141.

[14] Li, T., F. Song, J. Zhang, S. Liu, B. Xing and Y. Bai (2020). Pyrolysis characteristics of soil humic substances using TG-FTIR-MS combined with kinetic models. Science of The Total Environment, 698: 134237.

[15] Yu, J., N. Paterson, J. Blamey and M. Millan (2017). Cellulose, xylan and lignin interactions during pyrolysis of lignocellulosic biomass. Fuel, 191,140-149.

[16] Chen, X., Q. Che, S. Li, Z. Liu, H. Yang, Y. Chen, X. Wang, J. Shao and H. Chen (2019). Recent developments in lignocellulosic biomass catalytic fast pyrolysis: strategies for the optimization of bio-oil quality and yield. Fuel Processing Technology, 196, 106180.

[17] Shen, D. and S. Gu (2009). The mechanism for thermal decomposition of cellulose and its main products. Bioresource technology, 100(24), 6496-6504. 
[18] Collard, F.-X. and J. Blin (2014). A review on pyrolysis of biomass constituents: Mechanisms and composition of the products obtained from the conversion of cellulose, hemicelluloses and lignin. Renewable and Sustainable Energy Reviews, 38, 594-608.

[19] Oh, S. Y., D. I. Yoo, Y. Shin and G. Seo (2005). FTIR analysis of cellulose treated with sodium hydroxide and carbon dioxide. Carbohydrate research, 340(3), 417-428.

[20] Li, J., L.-P. Zhang, F. Peng, J. Bian, T.-Q. Yuan, F. Xu and R.-C. Sun (2009). Microwave-assisted solventfree acetylation of cellulose with acetic anhydride in the presence of iodine as a catalyst. Molecules, 14(9), 3551-3566.

[21] Abderrahim, B., E. Abderrahman, A. Mohamed, T. Fatima, T. Abdesselam and O. Krim (2015). Kinetic thermal degradation of cellulose, polybutylene succinate and a green composite: comparative study. World Journal of Environmental Engineering, 3(4), 95.

[22] Friedman, H. L. (1964). Kinetics of thermal degradation of char - forming plastics from thermogravimetry. Application to a phenolic plastic. Journal of Polymer Science Part C: Polymer Symposia, Wiley Online Library.

[23] Janković, B., N. Manić, I. Radović, M. Janković and M. Rajačić (2019). Model-free and model-based kinetics of the combustion process of low rank coals with high ash contents using TGA-DTG-DTA-MS and FTIR techniques. Thermochimica Acta, 679, 178337.

[24] Criado, J. M. (1978). Kinetic analysis of DTG data from master curves. Thermochimica Acta 24(1), 186189.

[25] Mallick, D., M. K. Poddar, P. Mahanta and V. S. Moholkar (2018). Discernment of synergism in pyrolysis of biomass blends using thermogravimetric analysis. Bioresource technology, 261, 294-305.

[26] White, J. E., Catallo, W. J., Legendre, B. L. (2011). Biomass pyrolysis kinetics: a comparative critical review with relevant agricultural residue case studies. Journal of analytical and applied pyrolysis, 91(1), 133.

[27] Collard, F.-X. and J. Blin (2014). A review on pyrolysis of biomass constituents: Mechanisms and composition of the products obtained from the conversion of cellulose, hemicelluloses and lignin. Renewable and Sustainable Energy Reviews, 38, 594-608.

[28] Mkhize, N., B. Danon, P. van der Gryp and J. Görgens (2019). Kinetic study of the effect of the heating rate on the waste tyre pyrolysis to maximise limonene production. Chemical Engineering Research and Design. $152,363-371$.

[29] Chin, B. L. F., S. Yusup, A. Al Shoaibi, P. Kannan, C. Srinivasakannan and S. A. Sulaiman (2014). Kinetic studies of co-pyrolysis of rubber seed shell with high density polyethylene. Energy conversion and management 87, 746-753.

[30] Wang, B., F. Xu, P. Zong, J. Zhang, Y. Tian and Y. Qiao (2019). Effects of heating rate on fast pyrolysis behavior and product distribution of Jerusalem artichoke stalk by using TG-FTIR and Py-GC/MS. Renewable Energy, 132, 486-496.

[31] Özsin, G. and A. E. Pütün (2019). TGA/MS/FT-IR study for kinetic evaluation and evolved gas analysis of a biomass/PVC co-pyrolysis process. Energy conversion and management 182, 143-153.

[32] Yan, J., H. Jiao, Z. Li, Z. Lei, Z. Wang, S. Ren, H. Shui, S. Kang, H. Yan and C. Pan (2019). "Kinetic analysis and modeling of coal pyrolysis with model-free methods." Fuel, 241, 382-391.

[33] Varhegyi, G., Jakab, E., Antal Jr, M. J. (1994). Is the Broido-Shafizadeh model for cellulose pyrolysis true?. Energy \& Fuels, 8(6), 1345-1352.

[34] Gronli, M., Antal, M. J., Varhegyi, G. (1999). A round-robin study of cellulose pyrolysis kinetics by thermogravimetry. Industrial \& Engineering Chemistry Research, 38(6), 2238-2244.

[35] Antal, M. J., Varhegyi, G., Jakab, E. (1998). Cellulose pyrolysis kinetics: revisited. Industrial \& Engineering Chemistry Research, 37(4), 1267-1275.

[36] Conesa, J. A., Caballero, J., Marcilla, A., Font, R. (1995). Analysis of different kinetic models in the dynamic pyrolysis of cellulose. Thermochimica Acta, 254, 175-192.

[37] Lin, Y. C., Cho, J., Tompsett, G. A., Westmoreland, P. R., Huber, G. W. (2009). Kinetics and mechanism of cellulose pyrolysis. The Journal of Physical Chemistry C, 113(46), 20097-20107.

[38] Capart, R., Khezami, L., Burnham, A. K. (2004). Assessment of various kinetic models for the pyrolysis of a microgranular cellulose. Thermochimica Acta, 417(1), 79-89. 
[39] Zhou, H., Long, Y., Meng, A., Chen, S., Li, Q., Zhang, Y. (2015). A novel method for kinetics analysis of pyrolysis of hemicellulose, cellulose, and lignin in TGA and macro-TGA. RSC Advances, 5(34), 2650926516.

[40] Vyazovkin, S., A. K. Burnham, J. M. Criado, L. A. Pérez-Maqueda, C. Popescu and N. Sbirrazzuoli (2011). "ICTAC Kinetics Committee recommendations for performing kinetic computations on thermal analysis data." Thermochimica acta 520(1-2): 1-19.

[41] Sobek, S. and S. Werle (2020). Kinetic modelling of waste wood devolatilization during pyrolysis based on thermogravimetric data and solar pyrolysis reactor performance. Fuel, 261, 116459.

[42] Singh, S., J. P. Chakraborty and M. K. Mondal (2020). Intrinsic kinetics, thermodynamic parameters and reaction mechanism of non-isothermal degradation of torrefied Acacia nilotica using isoconversional methods. Fuel, 259, 116263.

[43] Chong, C. T., G. R. Mong, J.-H. Ng, W. W. F. Chong, F. N. Ani, S. S. Lam and H. C. Ong (2019). Pyrolysis characteristics and kinetic studies of horse manure using thermogravimetric analysis. Energy Conversion and Management, 180, 1260-1267.

[44] Shahid, A., Ishfaq, M., Ahmad, M. S., Malik, S., Farooq, M., Hui, Z., Batawi, A. H., Shafi, M. E., Aloqbi, A. A., Gull, M., Mehmood, M. A. (2019) Bioenergy potential of the residual microalgal biomass produced in city wastewater assessed through pyrolysis, kinetics and thermodynamics study to design algal biorefinery, Bioresource Technology, 289, 121701. 